
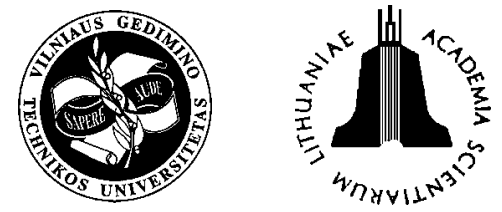

ISSN $1392-3730$

JOURNAL OF CIVIL ENGINEERING AND MANAGEMENT

http:/www.vtu.lt/english/editions

2004, Vol X, No 3, 235-239

\title{
CHANGES IN SUBJECTIVE ACOUSTICAL INDICATORS IN HALLS WITH LONG AND SHORT REVERBERATION TIMES
}

\author{
Vytautas J. Stauskis \\ Dept of Building Structures, Vilnius Gediminas Technical University, \\ Traku g. 1/26, LT-01132 Vilnius, Lithuania.E-mail: stauskis@ar.vtu.lt
}

Received 5 Apr 2004; accepted 31 May 2004

\begin{abstract}
Investigations of acoustics of halls of different types and volumes have disclosed good or acceptable values of the music sound clarity index $\mathrm{C}_{80}$, while the reverberation times of these halls were found to be either very short or very long. Subjectively, the acoustics of these halls are considered to be unsatisfactory. For example, the reverberation time measured in the hall of the Vilnius Opera and Ballet Theatre is about $1 \mathrm{~s}$, while the values of the $\mathrm{C}_{80}$ index are either good or acceptable. A church the volume of which is $22650 \mathrm{~m}^{3}$ has acceptable $\mathrm{C}_{80}$ values both in the performers's places and in the front rows. Similar results were obtained in other halls too.
\end{abstract}

Keywords: "Clarity" index $\mathrm{C}_{80}$, reverberation time, absorption, early energy, late energy, sound reflections.

\section{Introduction}

In order to evaluate the acoustics of existing halls or halls being designed, objective acoustic indicators and subjective energy indicators are to be measured. The voice clarity index $\mathrm{C}_{50}$ and the music sound clarity index $\mathrm{C}_{80}$ are widely used. It is possible to calculate these indices in the designing stage, though, much more exact results are offered by measured indices when a pulsed sound source is used. The music sound clarity index is a ratio between the early energy and the late energy The values of the index are different at varied points of the hall $[1-8]$. Its values are determined by the early sound reflections reaching the listener within the first $80 \mathrm{~ms}$. The structure of these reflections strongly depends on the positions of the sound source and the listener. If the sound source is located at the front of the stage and the hall itself is high and wide at this point, the first reflection will reach listeners relatively late, whereas listeners in the back rows of the hall will receive the first reflections much earlier [9-12]. Furthermore, the quantity of reflections received there within $80 \mathrm{~ms}$ will be much larger than that received in the first rows of the hall. The intensity of reflections which depends on the type of materials used for ceiling and wall planes is also important. After multiple reflection from all surfaces of the hall, energy will be lost and the energy losses will be directly proportional to the sound energy absorption by these surfaces. These will be late reflections reaching the listener after $80 \mathrm{~ms}$. The hall reverberation time, an important acoustic indicator, will also depend on these reflections.
Listeners are sensitive to the changes both in the intensity of early reflections and in the time during which the reflections arrive. Due to these reflections the listener may evaluate the dimensions and proportions of the hall and the work of music itself. Different structure and intensity of reflections determine different sounding of music at the front, middle and back rows of the hall.

In an attempt to evaluate the different reflection structures, the impact upon the listener, Reichardt et al [1-4] offered optimum values of the music sound clarity index $\mathrm{C}_{80}$ at the front and back rows of a hall. The authors of the study considered that, with the recommended values of $\mathrm{C}_{80}$, the hall acoustics will receive good subjective evaluation. The recommended values were accepted all over the world and for many years already have been used for evaluating the acoustic properties of halls. [13]. The question arises, however, as to whether optimum values of $\mathrm{C}_{80}$ are tantamount to good acoustics of a hall. It is understandable that the index alone is not sufficient for the evaluation. However, a good correlation between the $\mathrm{C}_{80}$ index and certain objective acoustic indicators has been found.

The purpose of this work is to determine the values of the music clarity index $\mathrm{C}_{80}$ at various points of actual halls with very different acoustic characteristics, to compare them with the recommended values, and to link them with the acoustic quality of the halls as evaluated by music specialists and the audience. 


\section{Subject of investigation}

Investigations into acoustics of halls of different types and volumes have shown that the values of the music sound clarity index are good or acceptable, while those of reverberation time, time centre of gravity, etc are completely unacceptable. Subjectively, acoustics of these halls are considered to be unsatisfactory.

In all cases the $\mathrm{C}_{80}$ values correspond to an unfiltered signal. At the same time, reverberation times, centre times of gravity and other indicators were calculated.

The clarity index $\mathrm{C}_{80}$ was calculated from experimental data by the formula $[1,2]$.

$$
C_{80}=10 \lg \frac{\int_{0}^{80} p^{2}(t) d t}{\int_{08}^{\infty} p^{2}(t) d t} .
$$

In order to establish the relationship between the change in the index $\mathrm{C}_{80}$ in halls of various types and at various points of the halls, six halls were selected. Their geometrical characteristics are presented in Table.

\begin{tabular}{c|l|c|c|c|c}
\hline No & Name of hall & $\mathrm{L}_{\max }$ & $\mathrm{B}_{\max }$ & $\mathrm{H}_{\max }$ & \multicolumn{1}{c}{$\mathrm{V}, \mathrm{m}^{3}$} \\
\hline 1 & $\begin{array}{l}\text { St. John's } \\
\text { Church }\end{array}$ & 58 & 25,5 & 20,5 & 27000 \\
\hline 2 & Cathedral & 56 & 24 & 19,8 & 22650 \\
\hline 3 & Cinema & 25 & 15 & 9,5 & 3306 \\
\hline
\end{tabular}

A calibre No 9 sound pistol was used as a sound source. It was located in the places usually occupied by performers. The microphone was placed in different rows along the hall. The sound signal was transmitted from the microphone to a 16-bit analog-to-digital converter having a wide dynamic range and stored into a computer memory. Afterwards the signals were analysed by means of a special computer program.

The reverberation times, time centres of gravity and other indicators of these halls were measured according to the requirements of the standard [14-16].

The investigations were conducted in unoccupied halls. When a hall is filled with listeners the overall hall absorption will increase and the reverberation time will be reduced. However, this reduction also depends on the chairs in the hall: the softer the chairs, the lesser the reduction attributed to the listeners. If a hall contains wooden benches, the reduction of the reverberation time will be much more marked. This will also produce effect on both early and late energy reaching the listeners, which, in its turn, will affect the clarity index $\mathrm{C}_{80}$. In order to establish the extent of change in the index with the presence of listeners and to determine whether such change may be examined in an unoccupied hall, investigations were conducted in the physical model of the hall (scale 1:25) and in two real halls.

\section{Dependence of the clarity index $C_{80}$ on changes in the hall's absorption}

For this purpose investigations were conducted in a physical model of the hall of scale 1:25. Placing soundabsorbing materials on various planes in the hall varied the overall absorption of the hall. The results of the investigation are shown in Fig 1.

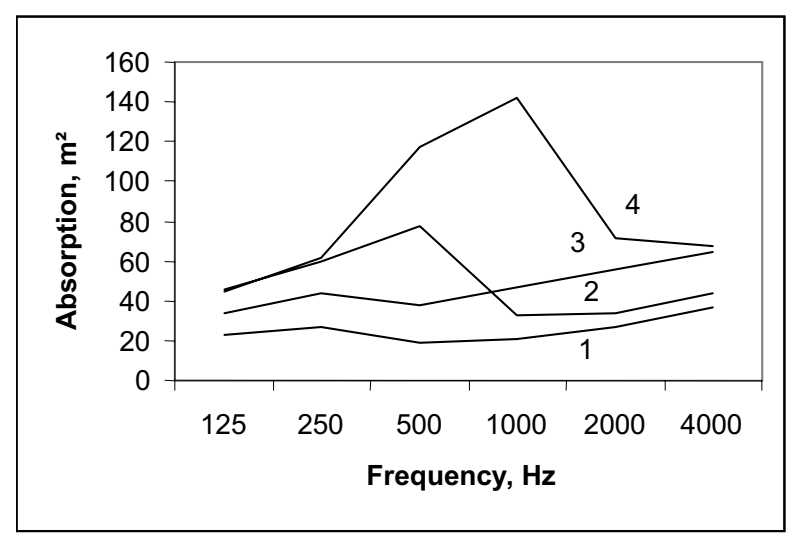

Fig 1. Dependence of sound absorption of the hall on location of sound-absorbing materials: 1 - hall without special absorbing materials; 2 - absorbing materials only on the ceiling; 3 - only on the floor; 4 - on the ceiling and the floor

When the absorbing materials are placed only on the ceiling, the maximum hall absorption is reached at $500 \mathrm{~Hz}$, and at high frequencies it is almost equal to the absorption of an empty hall. When such materials are placed only on the floor, the character of absorption changes entirely. Allocation of the materials both on the floor and the ceiling results in the maximum absorption only at $1000 \mathrm{~Hz}$, with almost no increase at low and high frequencies.

In practice, ceilings are only partially covered with absorbing materials. The audience fills the floor plane either by $100 \%$ or by $50 \%$. Their sitting positions may vary. The results of this investigation show that absorption changes, consequently, $\mathrm{C}_{80}$ index is subject to change as well. The results of the investigation for unfiltered signal are presented in Fig 2.

The graph clearly shows that the values of $\mathrm{C}_{80}$ increase with the increase in sound absorption. A 1,5-fold increase in absorption results in $\mathrm{a} \sim 3 \mathrm{~dB}$ increase in $\mathrm{C}_{80}$. This applies both to positive and negative values of $\mathrm{CC}_{80}$.

These results allow to draw a conclusion that listeners sitting on semi-upholstered or upholstered chairs in the hall cause no significant changes in the overall hall absorption. Therefore one may assert that the difference in the clarity index of the hall without listeners and the hall filled with listeners up to 70-80\% will make up only 1-3 dB. The presence of listeners/viewers will always increase and never reduce the clarity index. This 


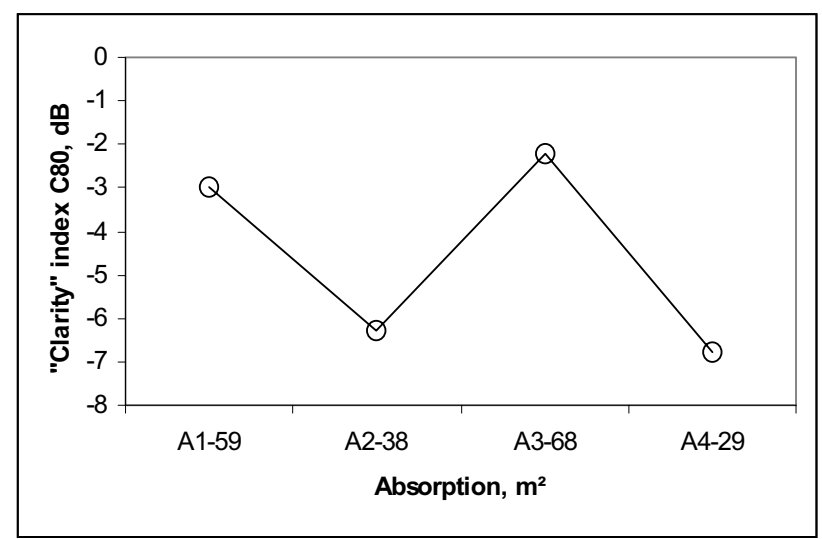

Fig 2. Dependence of Index $C_{80}$ on changes in the hall absorption. Figures denote sound absorption and letters denote location of absorbing materials: A1 - absorbing materials only on the floor; A2 - only on the ceiling; A3 - on the ceiling and the floor; A4 - no absorbing materials

means that changes in the clarity index may also be investigated in unoccupied halls.

\section{The change in the values of clarity index $C_{80}$ in churches}

Let us take an extreme example. In churches of St John and the Cathedral there is a very long reverberation time. The results of investigations are presented in Fig 3.

In the Cathedral church the values of $\mathrm{C}_{80}$ are good near the sound source and acceptable at the distance of $10 \mathrm{~m}$ from it. In St John church this distance is shorter and is equal to $5 \mathrm{~m}$. When listeners are present, the $\mathrm{C}_{80}$ values will undergo a considerable increase of about 3-4 $\mathrm{dB}$. Therefore it may be expected that they will be good and acceptable at a greater distance from the sound source. In such a case, even in the churches characterised by a long reverberation time, the index values are good and acceptable quite far from the sound source.

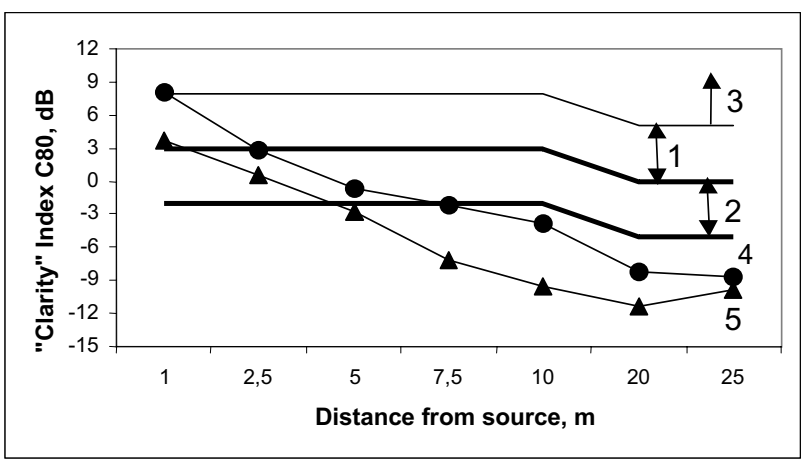

Fig 3. Changes in the clarity index in churches depending on the distance to the sound source: 1 - good values for front and back rows (lower and upper limits); 2, 3 - acceptable values for front and back rows (lower and upper limits); 4 - measured values - church No 2; 5 - measured values - church No 1
Fig 4 depicts the frequency characteristics of reverberation time. The volumes of these churches are very large and all surfaces are made of sound-reflecting materials. Both churches have benches made of hardwood.

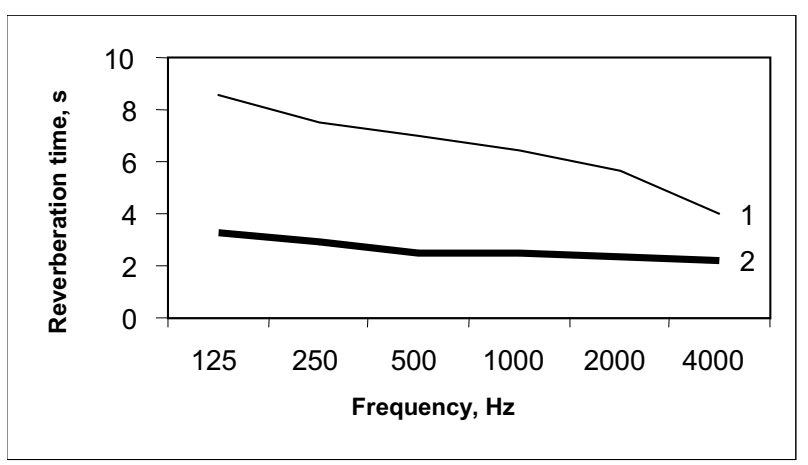

Fig 4. Frequency dependence on reverberation time: 1 measured in an unoccupied St John; 2 - recommended

The reverberation times in both churches are very long, particularly at low and medium frequencies. With 600 listeners present, the reverberation time is reduced by about $1-1,8 \mathrm{~s}$ but still remains very long and unacceptable from the point of view of good music sound. Fig 5 shows the results of investigation into the time centre of gravity.

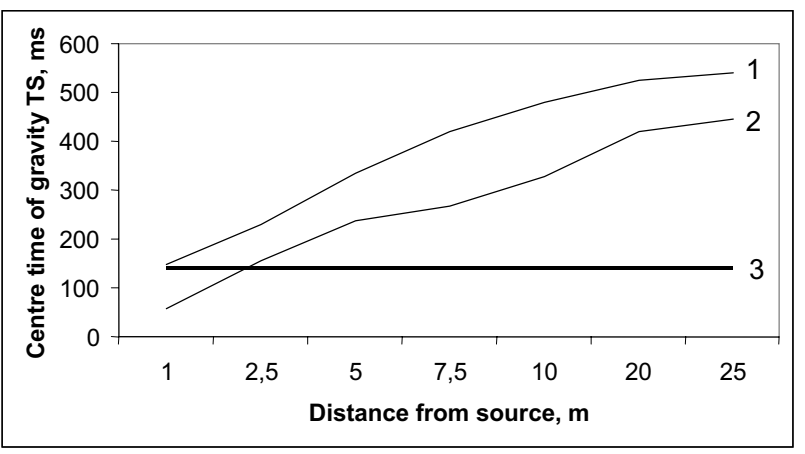

Fig 5. The dependence of the time of centre of gravity on the distance to the sound source: 1 - St. John church; 2 Cathedral church; 3 - maximal permitted values

Figure shows that the values of the time centre of gravity are very large when the distance from the sound source exceeds $2,5 \mathrm{~m}$. Large values of this indicator demonstrate the presence of echoes and long reverberation time of the hall.

\section{The change in the values of clarity index $C_{80}$ in the cinema hall}

This particular hall was selected for investigations because its acoustics are absolutely unsuitable for a natural sounding of music. Therefore it was interesting to observe the changes in the values of the clarity index $\mathrm{C}_{80}$ before and after the reconstruction of the hall. The 
Dolby Surround Digital sound recording system was installed in the hall.

For the installation the Dolby Surround Digital sound recording system, the reverberation time and the air volume resonances had to be strongly reduced. Therefore all walls and the ceiling of the hall were covered with sound-absorbing materials and the overall sound absorption was markedly increased after reconstruction. The results of investigations are presented in Fig 6.

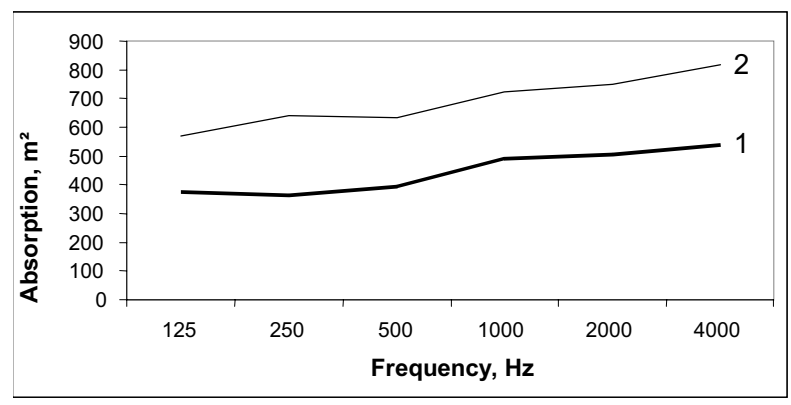

Fig 6. Frequency dependence of change in the overall sound absorption in the cinema hall: 1 - before reconstruction; 2 - after reconstruction

The graph shows that after the reconstruction the absorption has increased by about $230-250 \mathrm{~m}^{2}$ throughout the frequency range. The absolute values of absorption are large for a hall of such small volume.

Such marked changes in the sound absorption undoubtedly influence reverberation time, the results of investigation of which are shown in Fig 7.

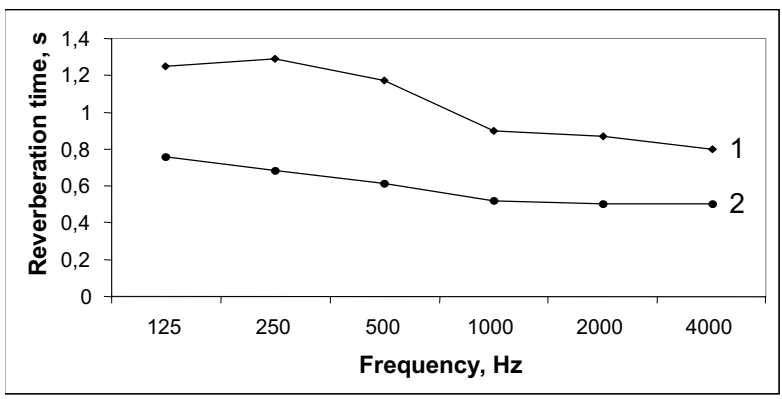

Fig 7. Frequency dependence of reverberation time in a cinema hall: 1- measured values before reconstruction; 2 - after reconstruction

Before the reconstruction the reverberation time values were 1,2-1,3 $\mathrm{s}$ at the low and medium frequencies and only $0,8-0,9 \mathrm{~s}$ at high frequencies. Such reverberation time is too low for a good sounding of music. After the reconstruction it was further reduced and is $0,8-0,5 \mathrm{~s}$ throughout the frequency range. Fig 8.

The values of the clarity index $\mathrm{C}_{80}$ are shown in

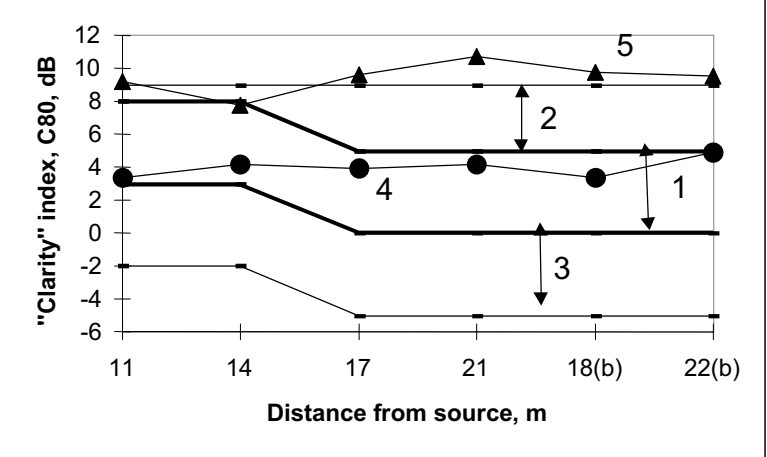

Fig 8. The change in the clarity index in the cinema hall depending on the distance to the sound source: $1-\operatorname{good}$ values for front and back rows (lower and upper limits); 2, 3 - acceptable values for front and back rows (lower and upper limits); 4 - measured values before reconstruction; 5 - after reconstruction

The index $\mathrm{C}_{80}$ values were good in all rows of the stalls and the balcony before reconstruction. After the reconstruction the reverberation time became much shorter but in spite of this the clarity index values are acceptable at the front rows of the stalls. It is obvious that no orchestra may sound well in such a hall. The values of the clarity index $\mathrm{C}_{80}$, however, were good at all points of the hall prior to reconstruction and remained good in the front rows even after the reconstruction.

Fig 9 shows the results of investigation of the time centre of gravity.

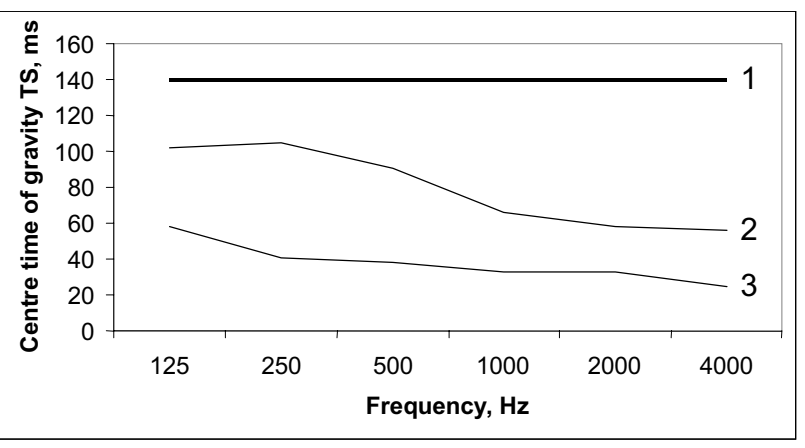

Fig 9. Dependence of the time centre of gravity on the distance to the sound source: 1 - maximal permitted values; 2 - measured values before reconstruction; 3 - after reconstruction

It can be seen from Fig 17 that the values of the time centre of gravity are very small both before and after the reconstruction. This demonstrates that the hall is very suppressed and all reflection energy is concentrated in the initial stage of the energy decrease.

Investigation results are presented for the halls of various type and volume, the acoustics of which have been subjectively recognised by music specialists as unsuitable for a natural sounding of music. This is confirmed by the investigations of objective indicators. In 
the churches, acceptable values were obtained at the performers' places and in the front rows of the hall. Even in the cinema hall, which is absolutely unsuitable for good sounding of music, the $\mathrm{C}_{80}$ values are good in all rows of the stalls. This means that the clarity index $\mathrm{C}_{80}$ may not be applied as an indicator for proper characterisation of the acoustics of a hall. Its recommended values should be adjusted. Furthermore, much acoustic information could be provided by the data on frequency dependence of this indicator.

The music sound clarity index is a ratio between the early energy and the late energy. It is determined by the structure of sound reflections which is different at various points of the same hall. For the front rows, good values are within the range of 3 to $8 \mathrm{~dB}$. This means that the early energy reaching the listener within the first $80 \mathrm{~m}$ must exceed the remaining pulse energy by $3-8 \mathrm{~dB}$. One may hardly agree with this. In order for the pulse energy from $80 \mathrm{~ms}$ to oo be lower by $3-8 \mathrm{~dB}$ than the early energy up to $80 \mathrm{~ms}$, the final process of energy decrease must be sufficiently quick. However, in such a case the hall reverberation will be short and this is undesirable in the halls used for music purposes. At the back rows, good values of $\mathrm{C}_{80}$ are within the range of 0 to $5 \mathrm{~dB}$. The ratio " 0 " shows a balance between the early energy and the late energy. Such balance is obtained in the Opera and Ballet Theatre (Fig 2) and the Small Hall of the Philharmonic Society (Fig 11). Due to higher intensity of reflections and longer reverberation time both the early and the late energy are larger in the concert hall than in the theatre, though the energy ratio is equal for both halls and the quality of music sound is quite different.

For instance, when an orchestra plays in the Opera Theatre, the first intensive reflection reaches the front rows of listeners after $23-25 \mathrm{~ms}$ and its amplitude is lower by $7,3-10,7 \mathrm{~dB}$ than that of the direct sound. No intensive reflections will be present in the interval between the direct sound and the first reflection. This interval will be filled by diffracted reflections with the intensity lower by $20-30 \mathrm{~dB}$ than that of the direct sound. At the back rows, the first reflections will reach the listener after 4 and $5 \mathrm{~ms}$ and their intensity will be lower by 9,1 and $12,8 \mathrm{~dB}$ respectively than that of the direct sound.

\section{Conclusions}

1) The presence of audience always increases the clarity index $\mathrm{C}_{80}$, the increase amounting to $1-3 \mathrm{~dB}$.

2) When the reverberation time is short and absolutely unacceptable in different halls, the values of the clarity index $\mathrm{C}_{80}$ are good or acceptable.

3) The values of the clarity index $\mathrm{C}_{80}$ are very different at different places of the same hall and they strongly depend on the positions of the sound source and the listener.

4) Recommended values of $\mathrm{C}_{80}$ are also found in the halls whose acoustics is assessed as bad or unacceptable by music specialists.

\section{References}

1. Reichadt, W.; Abdel Alim O, Schmidt, W. Definition and measurement basies of objective mass to determine limits between usable and unusable transparance in music. (Difinition und Messgrundlage eines objectiven Masses zur Ermittlung der Grenze zwischen brauchbarer und unbrauchbarer Durchsichtigkeit bei Musikdarbietungen). Acustica, 1975, Vol 32, No 3, p. 128-137 (in German).

2. Reichadt W. und Lehmann P. Room volume and transparance optimising in music by impulsive noise test (Optimierung von Raumeindruck und Durchsichtigkeit von Musikdarbietungen durch Auswertung von Impulsschalltest. Acustica, 1981, Vol 48, No 4, p. 174-185 (in German).

3. Lehmann, P.; Wilkens, H. Relation between subjective estimate and room acoustics in concert halls. (Zusammenhang der subjectiver Beurteilungen von Konzertsäle mit raumakustischen Kriterien). Acustica, 1980, Vol 45, No 4, p. 256-268 (in German).

4. Beranek, L. L. Audience and seat absorption in large halls. The Journal Acoustic Society of America, Vol 45, No 5, 1969, p. 13-19.

5. Bradley, J. S. Auditorium acoustic measures grom pistol Shots. The Journal Acoustic Society of America, Vol 80 (1), No 2, July 1986, p. 199-205.

6. Bradley, J. S. Experience width new auditorium acoustic Measurements. The Journal Acoustic Society of America, 73, 1983, No 4, p. 2051-2058.

7. Bradley, J. S. A comparison of three classical concert halls. The Journal Acoustic Society of America, 69 (3), No 2, 1991, March, p. 1176-1192.

8. Bradley, J. S. Acoustical comparison of three theaters. The Journal Acoustic Society of America, 79 (6), No 3, 1986, June, p. 1827-1832.

9. Beranek, L. L. Audience and seat Absorption in large halls. The Journal Acoustic Society of America, 45, No 4, 1969, p. $661-670$.

10. Kuttruff, H. Objective measurements in room acoustics. In: Reports of the 6th International Congress on acoustics, Vol 1, GP. P. Tokyo, 1968.

11. Kuttruf, H. Room Acoustics. New-York: Springer, 1991. $380 \mathrm{p}$.

12. Kuttruf, H. Reverberation and effective absorption in rooms with diffuze wall reflexions. Acustica, Vol 35, No 1, 1976, p. $141-153$.

13. Voelker, J. S. Home cinema surround sound - acoustics and neighbourhood. The 100th convention AES. Copenhagen, 1996. 7 p.

14. Lewers, T. H., Anderson, J. S. Some acoustical properties of St Paul's Catedral, London. Journal of Sound and Vibration, 1984, 92 (2), p. 285-297.

15. Thiele, R. About measuring of side noise in different halls in rooms (Richtungsverteilung und Zeitfolge der schallruckwurfe in Raumen). Acustica, 1953, Vol 3, No 4, p. 291302 (in German).

16. ICO 3382:1997(E). Acoustics. Measurement of the reverberation time of rooms with reference to other acoustical parameters. 